\title{
Pyloric balloon dilation for delayed gastric emptying in children
}

\author{
DM Israel MD FRCPC, G Mahdi MB BCh MRCPI, E Hassall MB BCh FRCPC
}

DM Israel, G Mahdi, E Hassall. Pyloric balloon dilation for delayed gastric emptying in children. Can J Gastroenterol 2001;15(11):723-727. Delayed gastric emptying may manifest with symptoms of epigastric pain, early satiety and delayed vomiting, and at times may be associated with failure to thrive. These symptoms and signs may improve following surgical pyloroplasty. To determine whether pyloric balloon dilation (PBD) is an effective therapy for children with these symptoms, hospital records of all children who underwent endoscopic PBD between October 1991 and March 1994 at British Columbia's Children's Hospital were reviewed. Excluded were children with chromosomal abnormalities, neurological disorders and erosive esophagitis. Through-the-scope balloons of diameter 15 or $18 \mathrm{~mm}$ were positioned in the pyloric channel and inflated with air to 2334 or $1815 \mathrm{mmHg}$ respectively, for $2 \mathrm{~min}$. Nineteen children with a mean age of 3.75 years (range eight months to 10 years) who presented with symptoms for more than three months (mean 11 months) were identified. Eleven children presented with failure to thrive, 14 with delayed vomiting and 10 with early satiety. Results of gastric emptying tests at $90 \mathrm{~min}$ ranged from $8 \%$ to $75 \%$ (mean $32 \%$ ). The pylorus was difficult to intubate in 11 of 19 children, and in two the pylorus could not be passed before PBD. No complications were experienced with PBD. Thirteen children had complete resolution of symptoms, and five had transient improvement lasting four to eight weeks after PBD with subsequent complete resolution of symptoms following surgical pyloroplasty. One child continued to have mild symptoms after PBD but did not have further treatment. This study suggests that PBD is a safe and effective therapeutic option in children with symptoms and signs associated with delayed gastric emptying.

Key Words: Delayed gastric emptying; Failure to thrive; Pyloric balloon dilation

pour le résumé voir page suivante

Division of Gastroenterology, British Columbia's Children's Hospital, Vancouver, British Columbia

Correspondence: Dr David M Israel, Division of Pediatric Gastroenterology, British Columbia Children's Hospital, 4480 Oak Street, Vancouver, British Columbia V6H 3V4. Telephone 604-875-2332, fax 604-875-3244, e-mail disrael@cw.bc.ca

Received for publication December 3, 1999. Accepted June 19, 2000 


\section{Dilatation pylorique par ballonnet pour retard de la vidange gastrique en pédiatrie}

RÉSUMÉ : Le retard de la vidange gastrique peut se manifester par des symptômes de douleurs épigastriques, de satiété précoce, de vomissements et parfois, par un retard de croissance. Ces symptômes et ces signes peuvent s'améliorer après une pyloroplastie chirurgicale. Pour déterminer si la dilatation pylorique par ballonnet (DPB) est un traitement efficace chez les enfants présentant de tels symptômes, les dossiers hospitaliers de tous les enfants ayant subi une DPB entre octobre 1991 et mars 1994 au British Columbia Children's Hospital ont été passés en revue. Les enfants présentant des anomalies chromosomiques, des troubles neurologiques et une œsophagite érosive ont été exclus. Des ballonnets endoscopiques d'un diamètre de 15 ou $18 \mathrm{~mm}$ ont été installés au niveau du pylore et gonflés avec de l'air (à 2334 ou $1815 \mathrm{~mm} \mathrm{Hg}$ ), respectivement pendant deux minutes. Dix-neuf enfants âgés en moyenne de 3,75 ans (de 8 mois à 10 ans), dont les symptômes duraient depuis plus de trois mois (en moyenne 11 mois), ont été identifiés. Onze enfants présentaient un retard de croissance, 14 souffraient de vomissements et 10 de satiété précoce. Les résultats des tests de vidange gastrique au bout de 90 minutes variaient de 8 à $75 \%$ (moyenne $32 \%$ ). Le pylore a été difficile à intuber chez 11 enfants sur 19 et impossibles à intuber dans deux cas avant la DPB. Aucune complication n'a été associée à cette intervention. Les symptômes sont entièrement rentrés dans l'ordre chez 13 enfants. Cinq ont manifesté une amélioration transitoire de 4 à 8 semaines après la DPB avec résolution complète des symptômes après une pyloroplastie chirurgicale. Un enfant a continué de présenter de légers symptômes après la DPB, mais n'a pas eu besoin d'autres traitements. Cette étude donne à penser que la DPB est une option thérapeutique sûre et efficace chez les enfants qui présentent des signes et symptômes de retard de la vidange gastrique.
Tn children and adults, delayed gastric emptying (DGE) 1 may manifest with symptoms of epigastric pain, early satiety and delayed vomiting (1-4), which may result in failure to thrive (FTT) $(5,6)$. Although gastric emptying is effected by complex neuronal and hormonal mechanisms that coordinate gastric, pyloric and duodenal motility (711), delayed emptying may improve with simple mechanical manipulation of the pylorus. For example, surgical pyloroplasty has been successful in correcting DGE in children with functional or mechanical gastric outlet obstruction, and resulted in catch-up weight gain $(5,6)$. Similarly, we have previously observed complete resolution of FTT and delayed vomiting associated with DGE in four children (age range one to three years) following surgical pyloroplasty. Following this observation, we offered pyloric balloon dilation (PBD) as a less invasive approach to improving gastric drainage in children with symptoms associated with DGE who were unresponsive to cisapride and were undergoing diagnostic upper gastrointestinal endoscopy. Informed consent for PBD was obtained before endoscopy. The outcome of PBD in this selected group of children is described.

\section{PATIENTS AND METHODS}

To determine the success rate of PBD in children with frequent delayed vomiting and/or early satiety, the hospital records of all children who underwent endoscopic PBD and had one or both of these symptoms between October 1991 and March 1994 at British Columbia's Children's Hospital were reviewed. 'Delayed vomiting' was defined as vomiting of gastric contents several times per week occurring more than $1 \mathrm{~h}$ after a meal, and 'early satiety' as self-limiting of meal size in infants or complaints of early 'fullness' in older children. Children with chromosomal abnormalities or neurological disorders were excluded from the study group because of difficulty in assessing a response to treatment. Children with erosive esophagitis were also excluded because they were treated with omeprazole, which may improve their symptoms regardless of PBD (12).

In children with frequent or forceful vomiting, it was standard practice to rule out malrotation and anatomical abnormalities by upper gastrointestinal series. Children with delayed vomiting or early satiety were evaluated by a gastric emptying study performed with $99 \mathrm{~m}_{\text {technetium sul- }}$ phur meals; normal was defined as over 50\% emptying of gastric content at $90 \mathrm{~min}(13,14)$. Young infants and toddlers were given formula or yogourt as a test meal, while older children were fed two eggs or a tuna sandwich. All children with these symptoms were then treated with cisapride $(0.3$ to $0.5 \mathrm{mg} / \mathrm{kg} /$ dose qid) for at least four weeks. When upper gastrointestinal endoscopy was indicated to evaluate upper gastrointestinal symptoms, PBD was offered and specific consent was obtained. During the endoscopy, a through-the-scope balloon (Microvasive Inc, USA) of diameter either 15 or $18 \mathrm{~mm}$ was positioned in the pyloric channel under direct vision and inflated with air to 2334 or $1815 \mathrm{mmHg}$ respectively, for a period of $2 \mathrm{~min}$. The $15 \mathrm{~mm}$ balloon was used for children under six years of age, and the $18 \mathrm{~mm}$ balloon for older children.

Outcome assessment was by symptoms and signs as reported by the parents and by documentation of growth data. Symptoms and signs were considered to have completely resolved if absent for at least three months after PBD. A repeat gastric emptying study was planned only for patients with incomplete symptomatic relief following PBD. Patients who had only transient resolution of symptoms or signs after PBD were offered surgical pyloroplasty or repeat PBD at the parents' discretion.

Over the years, it has been the authors' practice to document in endoscopy reports the presence of a normal or 'tight' pylorus; 'tight' was defined as difficulty in passage of the endoscope through the pylorus without some forceful manipulation of the tip. The finding of this so-called 'tight' pylorus appears to represent a mismatch between the diameter of an endoscope, usually selected based on the size of the child, and the diameter of the pylorus in that child. To determine whether an apparently 'tight' pylorus was simply due to the happenstance selection of too large an endoscope for a given child, the authors attempted to characterize a 'reference group'. For this purpose, reports of all upper gastrointestinal endoscopies performed between August 1994 and September 1995 of all the children who had 
endoscopies and did not present with symptoms or signs suggestive of DGE were reviewed. Data were collected regarding the child's age, indication for the procedure, endoscope size and any difficulty in passing the pylorus. Statistical analysis was done using the $\chi^{2}$ test.

\section{RESULTS}

The study group consisted of 19 children with a threemonth or longer duration of follow-up after PBD; 11 boys and eight girls, eight months to 10 years of age (mean 3.75 years), had a mean follow-up of 11 months. Eleven of 19 presented with FTT, defined as weight below the fifth percentile or a decrease in growth of more than two major growth percentiles. Of the 11 children with FTT, there were seven boys and four girls, 14 months to 3.8 years of age (mean 3.5 years), with a mean follow-up of 13.4 months. The eight children without FTT comprised four boys and four girls, six months to 10 years of age (mean 5.1 years), with a mean follow-up of 8.5 months.

Figure 1 shows the main symptoms and signs in the 19 children before and after PBD. Thirteen children had complete resolution of symptoms following PBD (68\%). Five of 19 had transient improvement of symptoms lasting four to eight weeks after PBD; four of the five had a second PBD with transient response, and all five had complete resolution of the symptoms following surgical pyloroplasty. One child with intermittent vomiting did not respond to PBD and did not undergo repeat PBD or pyloroplasty; this child continued to have mild symptoms. All five children with both early satiety and FTT responded, as did five of seven children presenting with vomiting alone. Overall, 18 of 19 (95\%) children responded to either PBD or surgical pyloroplasty.

Growth has improved for all 11 children with FTT. Overall, these children had a mean weight below the 10th percentile before PBD and a mean weight in the 25th percentile after PBD. Five of these children were below the fifth percentile before PBD compared with only two after PBD. One of these two children grew from $5 \mathrm{~kg}$ below the fifth percentile to $3 \mathrm{~kg}$ below, and the other resumed a normal growth rate. Two children had accelerated growth and crossed two growth curves up (25\% to $75 \%, 5 \%$ to $50 \%$ ).

Results of pre-PBD gastric emptying tests ranged from $8 \%$ to $75 \%$ at 90 min (mean 32\%). Four children had gastric emptying of $10 \%$ or less, seven between $11 \%$ and $30 \%$, five between $31 \%$ and $50 \%$, and three over $50 \%$. Post-PBD gastric emptying tests were available for only four children with persistent or recurring symptoms. Their gastric emptying test rates after PBD were $13 \%, 13.5 \%, 36 \%$ and $48 \%$ (mean 27\%); these rates were faster than their pre-PBD study results of $9 \%, 9 \%, 23 \%$ and $8 \%$, respectively (mean $12.25 \%)$, but were still slower than normal.

Performing PBD during upper gastrointestinal endoscopy added less than $5 \mathrm{~min}$ to the procedure. There were no mucosal abnormalities of the upper gastrointestinal tract at endoscopy in any child; more specifically, no ulcers were seen. In all cases, obvious blanching of the pyloric ring

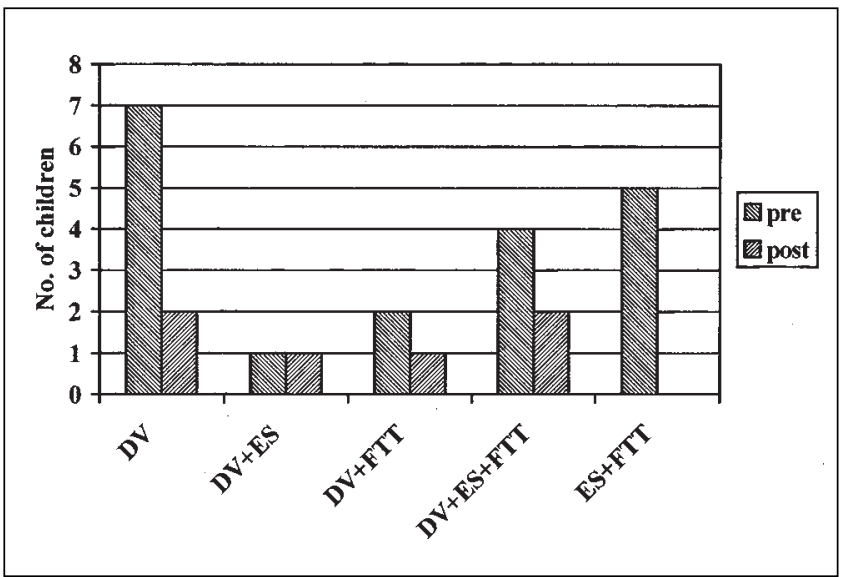

Figure 1) The main presenting symptoms and signs for 19 children before and after initial pyloric balloon dilation. The y axis represents the number of children with a given symptom or symptom complex shown on the $x$ axis. DV Delayed vomiting; ES Early satiety; FTT Failure to thrive

was seen at endoscopy when the through-the-scope balloon was fully inflated. After balloon deflation, mucosal breaks at the pyloric ring were usually present with minimal oozing of blood, but no active bleeding occurred. In 11 of 19 (58\%) children, the pylorus was described as 'tight', and in two of the 11, passage of the endoscope tip through the pylorus was impossible before dilation using endoscopes with an external diameter of $9 \mathrm{~mm}$ or $11.2 \mathrm{~mm}$. In all 11 children with a 'tight' pylorus, symptoms responded to PBD alone without the need for pyloroplasty. In contrast, PBD resulted in lasting improvement in only two of eight children in whom it was easy to pass the endoscope through the pylorus.

Between August 1994 and September 1995, 199 children, with an age distribution similar to that of the PBD group, had upper gastrointestinal endoscopies; these patients comprised the 'reference group'. None of these children had frequent vomiting or early satiety. Of the 199 children, 20 were recorded as having a 'tight' pylorus using the same range of endoscope diameters. Thus, only $10 \%$ of the reference group had a 'tight' pylorus compared with $58 \%$ in the study group $(\mathrm{P}<0.001)$. Within the 'reference group', there were 106 children younger than four years of age (mean 1.9 years); it was difficult to pass endoscopes with an external diameter of $9.0 \mathrm{~mm}$ or $9.8 \mathrm{~mm}$ through the pylorus in only $15(14 \%)$ cases. The same sizes of endoscopes were used in 13 of the 19 children in the PBD group. Even though these children were somewhat older (mean age 7.7 years), it was difficult to pass the endoscopes with an external diameter of $9.0 \mathrm{~mm}$ or $9.8 \mathrm{~mm}$ in seven of the 13 children $(\mathrm{P}<0.001)$.

\section{DISCUSSION}

The present study describes a selected group of children with delayed vomiting, early satiety and FTT who failed to respond to cisapride, but who did respond to $\mathrm{PBD}$ or surgical pyloroplasty. There was a significantly higher preva- 
lence of 'tight' pylorus in children with these symptoms compared with children undergoing endoscopy for other indications. This does not imply that pyloric abnormalities are solely responsible for the delay in gastric emptying, but rather indicates that pyloric manipulation is a potential treatment for children with these symptoms.

In adults, endoscopic balloon dilation for nonmalignant (ie, peptic) gastric outlet obstruction usually has an immediate benefit and is safe, but has not been uniformly successful in the long term (14-16). There are only a few case reports of successful PBD in children as a treatment for acquired gastric outlet obstruction secondary to peptic ulcer or caustic ingestion $(17,18)$.

How may PBD work?: The contractile activities of the gastric fundus, the antrum, the pylorus and the duodenum are involved in the transpyloric movement of luminal contents (8). Recent studies of gastric emptying relate pyloric motility to pyloric opening and closure, and to transpyloric flow (7-11). Gastric emptying occurs as a result of the antroduodenal transpyloric pressure gradient, which is limited by pyloric resistance. Under different conditions, gastric emptying is controlled via neuronal and humoral mechanisms (19-22), which effect gastric emptying by serial luminal occlusion of the antrum and pylorus $(8,9)$. We speculate that PBD may allow for a larger pyloric channel opening with lower resistance to flow at the time of pyloric relaxation, without preventing pyloric occlusion in response to the intrinsic gastroduodenal control mechanisms. This decrease in transpyloric resistance may result in improved gastric emptying, regardless of the mechanism responsible for the delay. It is interesting to note that five children had transient or partial improvement following PBD and complete resolution of symptoms after surgical pyloroplasty. None of these five children had a 'tight' pylorus at endoscopy, even though their gastric emptying rates were among the slowest. It is possible that, in these cases, the main factor in delaying gastric emptying was gastroduodenal motility and not pyloric size, but that gastric emptying was improved by opening the pylorus and reducing resistance to flow.

Of the 13 children in whom PBD was successful, the pylorus was described as 'tight' in 11, possibly implicating pyloric channel size as a major factor causing DGE in these children. The etiology of this 'tight' pylorus is unclear. These children did not have congenital hypertrophic pyloristenosis, a well-recognized disorder that typically presents within the first one to four months of age, with projectile vomiting and a markedly narrowed pyloric channel due to significant pyloric muscle hypertrophy. All of the children in our series had had at least one upper gastrointestinal barium study, some had had abdominal ultrasound and five had undergone surgical pyloroplasty; none had findings suggestive of the exuberant pyloric muscle hypertrophy that characterizes the congenital disorder. It is possible that some of our patients may have had a subtler variant of that disorder, with mild muscle hypertrophy responding to forceful dilation. Because these older patients do not have muscular hypertrophy of any severity, the risk of rupture of the pylorus by PBD appears to be minimal.

How much should the pylorus be dilated?: Most of the literature on PBD is related to adults with nonmalignant or benign pyloristenosis. In adults, gastric outlet obstruction was defined as the inability to pass an endoscope with an external diameter of $9.0 \mathrm{~mm}$ or $9.8 \mathrm{~mm}$ through the pylorus (15), and most adults with gastric outlet obstruction become symptomatic when the diameter of the antroduodenal segment is below $10 \mathrm{~mm}$ (23). Only a few published pediatric studies have provided information on the pyloric channel size of different age groups. In infants, an endoscope with an external diameter of $5.2 \mathrm{~mm}$ can be passed through the pylorus (24), and a failure to pass an endoscope with an external diameter of $7.8 \mathrm{~mm}$ through the pylorus is considered a sign of hypertrophic pylorus (25). In most children over one year of age in the 'reference group', endoscopes with an external diameter of $9.0 \mathrm{~mm}$ or $9.8 \mathrm{~mm}$ could be passed without difficulties. In children with gastric outlet obstruction, symptoms improved dramatically following dilation with balloons with an external diameter of 10 to $20 \mathrm{~mm}(17,18)$. Based on these data, it can be concluded that the pylorus should be dilated to a diameter greater than $10 \mathrm{~mm}$.

When observing PBD under fluoroscopy, a contrastfilled balloon initially shows a 'waist' that usually disappears within 2 min of dilation (26). It has been suggested that once 'waisting' disappears, the radial effect of the dilation is achieved and prolongation of the procedure is not necessary (26). While dilation periods have varied from $30 \mathrm{~s}$ to $10 \mathrm{~min}$, most large adult series have used $60 \mathrm{~s}$ or $3 \mathrm{~min}(16,27,28)$ with good long term outcome (27). A duration of 2 to 3 min appears to be optimal; furthermore, based on our experience, there does not appear to be a need for routine fluoroscopy in PBD.

How safe is pyloric dilation?: In adults, in whom the main indication for PBD is peptic pyloric stricture, the main reported complication in association with PBD is an acute perforation in about $7 \%$ of cases. Perforation is more likely when dilating the pyloric channel over $16 \mathrm{~mm}$, and more so when a $20 \mathrm{~mm}$ balloon is used. Perforations have not been reported with balloons $15 \mathrm{~mm}$ or smaller $(23,28)$. However, these results may not apply to children with symptoms associated with DGE because the pylorus in these cases has no apparent scarring. We have not observed any complications when performing PBD for this indication.

Based on these safety and efficacy data, we recommend the use of a 2 min dilation period and a 15 or $18 \mathrm{~mm}$ diameter balloon. In general, we use the $15 \mathrm{~mm}$ balloon for children under six years of age and the $18 \mathrm{~mm}$ balloon for older children. We do not perform PBD on infants with congenital hypertrophic pyloristenosis; in patients with this disorder, there is a risk of pyloric rupture with balloon dilation (29), likely due to the high degree of resistance offered by the marked muscle hypertrophy present. The surgical (Ramstedt) procedure is short, safe and effective, and we see no reason to replace it with PBD. 
In children with only transient or partial clinical response, a repeat PBD or surgical pyloroplasty should be considered. While pyloroplasty is a relatively minor surgical procedure, it has a $2.3 \%$ risk of duodenal perforation (30) and a risk of developing dumping syndrome. For these reasons, surgery should not be offered as the initial approach for children with symptoms associated with DGE.

The present report shows that PBD is a safe and effective treatment option for children presenting with frequent delayed vomiting, early satiety and FTT. The procedure can be performed in children with minimal prolongation of endoscopic procedure time. We recommend that a pyloric balloon size of either 15 or $18 \mathrm{~mm}$ be used and that the dilation period be kept to 2 to $3 \mathrm{~min}$. Further data to establish proper patient selection for PBD and further assessment of its effectiveness for this indication are required.

\section{REFERENCES}

1. Hillemeier AC, Lange R. Delayed gastric emptying in infants with gastroesophageal reflux. J Pediatr 1981;98:190-3.

2. Hillemeier AC, Grill BB, McCallum R, Gryboski J. Esophageal and gastric motor abnormalities in gastroesophageal reflux during infancy. Gastroenterology 1982;84:741-6.

3. Cucchiara S, Bortoloti M, Colombo C, et al. Abnormalities of gastrointestinal motility in children with nonulcer dyspepsia and in children with gastroesophageal reflux disease. Dig Dis Sci 1991:36:1066-73.

4. van Wijk HJ, Smout AJPM, Akkermans LMA, Roelofs JMM, ten Thije OJ. Gastric emptying and dyspepsia in the irritable bowel syndrome. Scand J Gastroenterol 1992;27:99-102.

5. Mulvihill SJ, Fonkalsrud EW. Pyloroplasty in infancy and childhood. J Pediatr Surg 1983;18:930-6.

6. Fonkalsrud EW, Ament ME, Vargas J. Gastric antroplasty for the treatment of delayed gastric emptying and gastroesophageal reflux in children. Am J Surg 1992;164:327-31.

7. Tougas G, Anvari M, Dent J, Somers J, Richard D, Stevenson GW. Relation of pyloric opening and closure in healthy subjects. Gut 1992;33:466-71

8. Houghton LA, Read NW, Heddle R, et al. Motor activity of the gastric antrum, pylorus, and duodenum under fasted conditions and after a liquid meal. Gastroenterology 1988;94:1276-84.

9. Houghton LA, Read NW, Heddle R, et al. Relationship of the motor activity of the antrum, pylorus, and duodenum to gastric emptying of a solid-liquid mixed meal. Gastroenterology 1988;94:1285-91

10. Melbert $\mathrm{CH}$, Mathis C. Antropyloric modulation of transpyloric flow of liquid in pigs. Gastroenterology 1994;107:37-46.

11. Horowitz M, Dent J. The study of gastric mechanics and flow: A mad hatter's tea party starting to make sense? Gastroenterology 1994;107:302-6.

12. Gunasekaran TS, Hassall E. Efficacy and safety of omeprazole for severe gastroesophageal reflux in children. J Pediatr 1993;123:148-54

13. Heyman S, Eicher PS, Alavi A. Radionuclide studies of the upper gastrointestinal tract in children with feeding disorders. J Nucl Med 1995;36:351-4.

14. Nadel HR, Hassall EG, Rimanic AL. A technique for pediatric gastric emptying scintigraphy. J Nucl Med 1988;29:979. (Abst)

15. Kuwada SK, Alexander GL. Long term outcome of endoscopic dilation of nonmalignant pyloric stenosis. Gastrointest Endosc 1995;41:15-7.

16. Benjamin SB, Cattau EL, Glass RL. Balloon dilatation of the pylorus: Therapy for gastric outlet obstruction. Gastrointest Endosc 1982;28:253-4.

17. Chan KL, Saig H. Balloon catheter dilatation of peptic pyloric stenosis in children. J Pediatr Gastroenterol Nutr 1994;18:465-8.

18. Treem WR, Long WR, Friedman D, Watkins JB. Successful management of an acquired gastric outlet obstruction with endoscopy guided balloon dilatation. J Pediatr Gastroenterol Nutr 1987;6:992-6.

19. Holle GE, Steinbach E, Forth W. Intrinsic corpoantropyloric coordination of motility and gastric emptying. Am J Physiol 1994:29:G255-62.

20. Holle GE, Hahn D, Forth W. Innervation of pylorus in control of motility and gastric emptying. Am J Physiol 1992;26:G161-8.

21. Moran TH, Crosby RJ, McHugh PR. Effect of pylorectomy on cholecystokinin-induced inhibition of liquid gastric emptying. Am J Physiol 1991;261:R531-5.

22. Treacy PJ, Jamieson GG, Dent J, Devitt PG, Heddle R. Duodenal intramural nerves in control of pyloric motility and gastric emptying. Am J Physiol 1992;26:G1-5.

23. DiSario JA, Tietze CC, Huston WR, Burt RW. Endoscopic balloon dilatation for ulcer-induced gastric outlet obstruction. Am J Gastroenterol 1994;89:868-71

24. Ruuska T, Fell JME, Bisset WM, Milla PJ. Neonatal and infantile upper gastrointestinal endoscopy using a new small diameter fiberoptic gastroscopes. J Pediatr Gastronterol Nutr 1996;23:604-8.

25. De Baker A, Bore T, Vandenplas Y, Peters S, Deconinck P. Contribution of endoscopy to early diagnosis of hypertrophic pyloric stenosis. J Pediatr Gastroenterol Nutr 1994;18:78-81.

26. Griffin SM, Chung SCS, Leung JWC, Li AKC. Peptic pyloric stenosis treated by endoscopic balloon dilatation. Br J Surg 1989;76:1147-8.

27. Kozarek RA, Botoman VA, Patterson DJ. Long-term follow-up in patients who have undergone balloon dilation for gastric outlet obstruction. Gastrointest Endosc 1990;36:558-61.

28. Lau JYW, Chung S, Sung JJY, et al. Through-the-scope balloon dilation for pyloric stenosis: long-term results. Gastrointest Endosc 1996;43:98-101.

29. Hayashi AH, Giacomantonio JM, Lau HY, Gillis DA. Balloon catheter dilatation for hypertrophic pyloric stenosis. J Pediatr Surg 1990;25:1119-21.

30. Benson CD. Infantile hypertrophic pyloric stenosis. In: Welch KJ, Randolph JG, Ravitch MM, O’Neill JA, Rowe MI, eds. Pediatric Surgery. Chicago: Year Book Medical Publishers, Inc, 1985:811-5. 


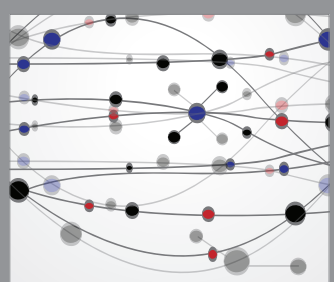

The Scientific World Journal
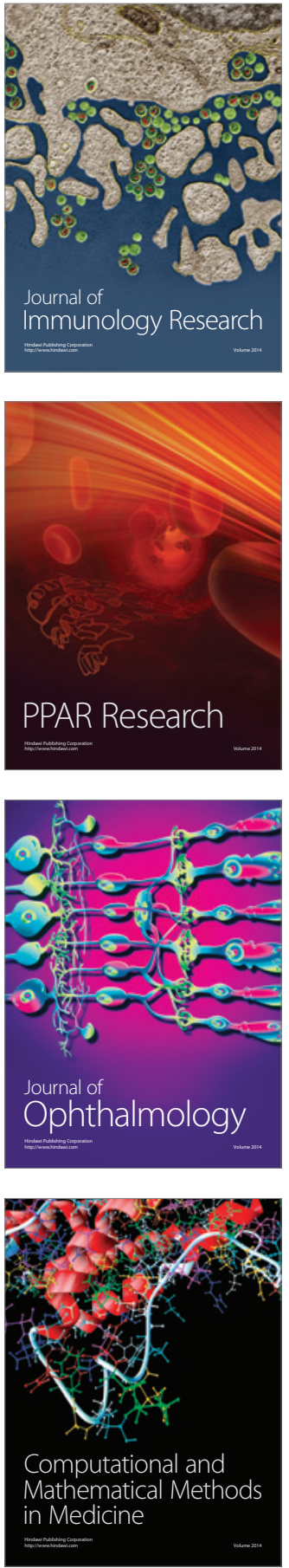

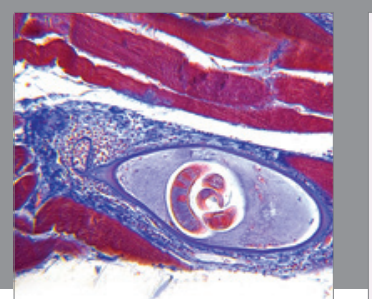

Gastroenterology Research and Practice

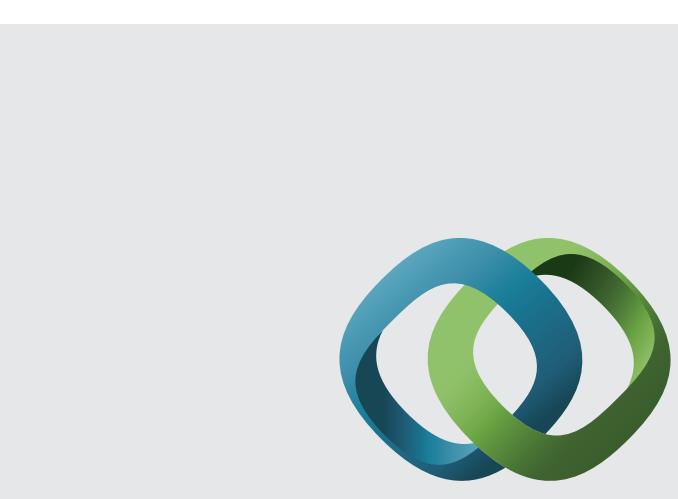

\section{Hindawi}

Submit your manuscripts at

http://www.hindawi.com
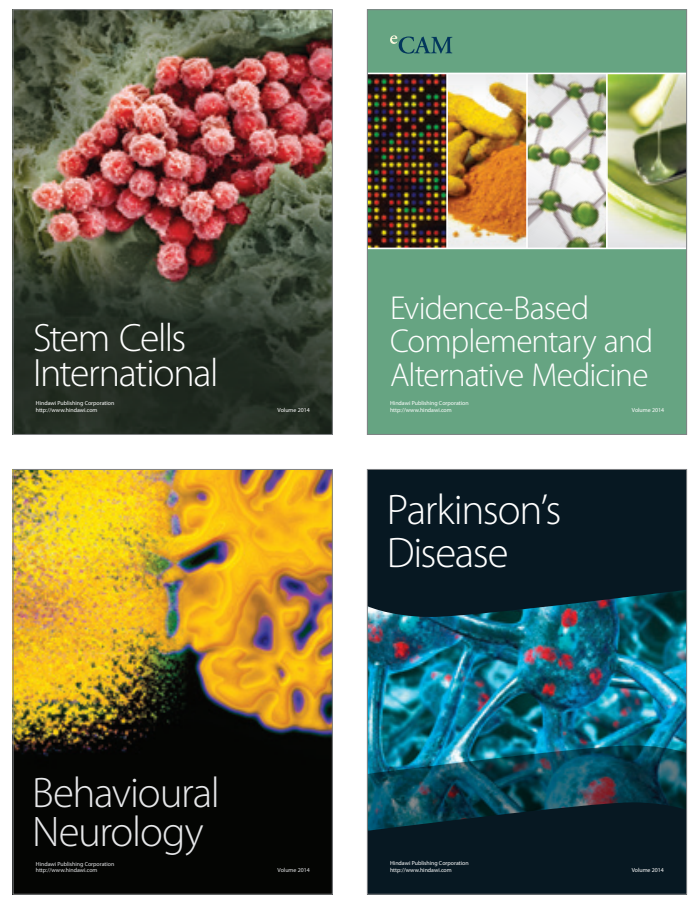
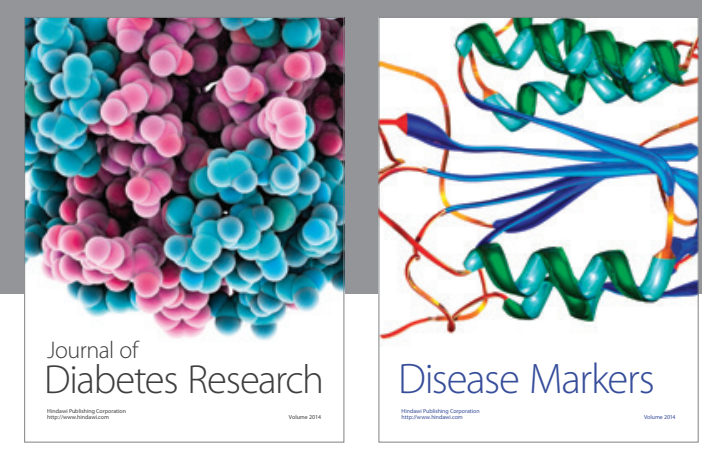

Disease Markers
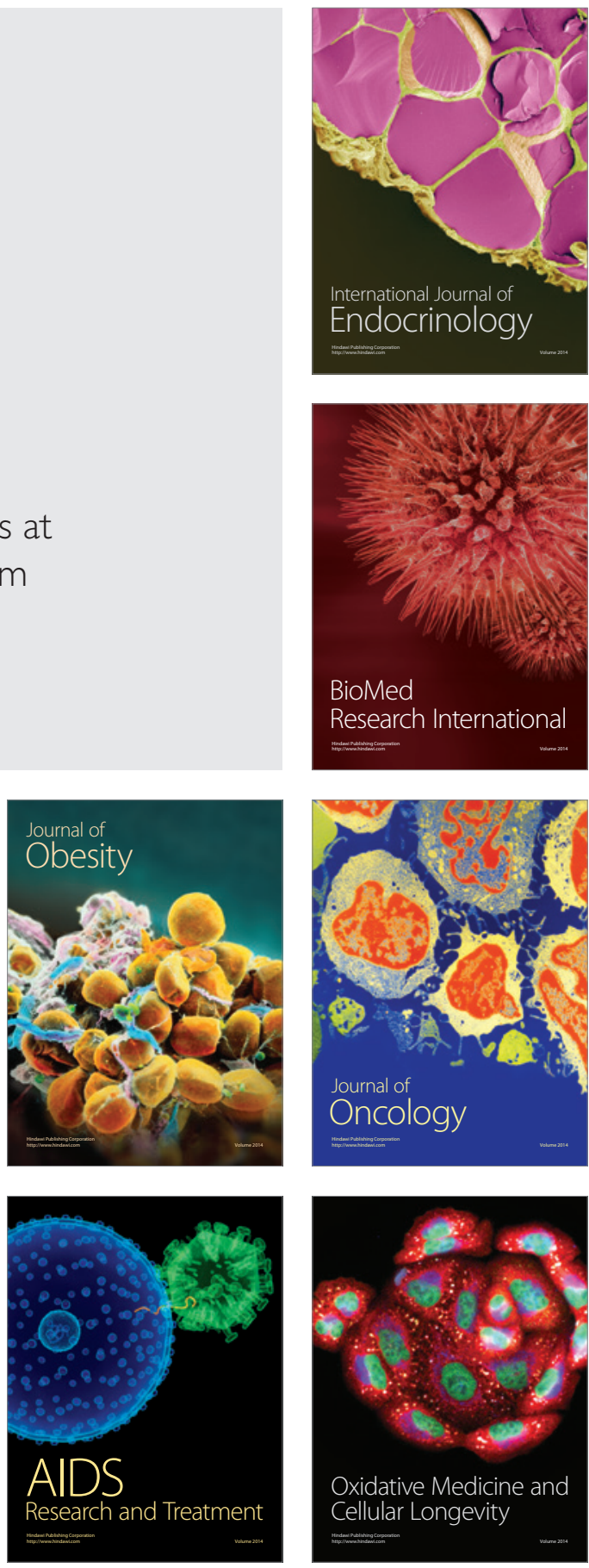